\title{
Biodiversity, Big Data and Genome Editing
}

\section{Calvin W. L. Ho ${ }^{1}$ (D) Adrienne Hunt ${ }^{2}$}

Published online: 19 June 2019

(C) National University of Singapore and Springer Nature Singapore Pte Ltd. 2019

In 2018, we concluded the year with the publication of a special journal issue on the bioethical aspects of biodiversity conservation. It is a topic that has not until now received much attention from this journal, even though the Asia Pacific region is exceptionally rich in biodiversity, both on land and at sea (UNEP-WCMC 2016). This richness makes more apparent what we - as inhabitants of this region - and as humankind more generally stand to lose in the foreseeable future. The recently published global assessment report of the Intergovernmental Science-Policy Platform on Biodiversity and Ecosystem Services (2019) estimates that, globally, an astounding one million species are at risk of extinction if urgent actions are not taken to avert this eventuality. As an enterprise concerned with understanding life and enabling human flourishing, how then should bioethics and its communities respond to this pressing and complex set of challenges? While not in any way purporting to have the answers, this journal reiterates its intent to sustain a forum for cross-disciplinary dialogue that will hopefully add clarity to the actions that are needed, as well as the normative justifications for them. It is therefore fitting that we begin this second journal issue for the year with a reaction (Duffillot 2019) to Nicolas Lainé's (2018) paper that was published in the aforementioned special issue, and a response by him and Serge Morand (Lainé and Morand 2019) to this reaction. In the same vein, we are delighted to present a paper by Serge Morand and Claire Lajaunie (Morand and Lajaunie 2019), which seeks to draw together a number of themes that underscore the special issue on biodiversity conservation that they guest edited (Lajaunie and Morand 2018).

Additionally, we are delighted to present an instructive commentary by Kanny Ooi (2019) on a paper by Shivkrit Rai and Vishwas Devaiah (Rai and Deviah 2019), published by this journal earlier in the year. This is followed by a special section of the journal issue on Big Data, ably put together by Owen Schaefer. The papers in this special section are introduced in his section editorial. Finally, we take this opportunity to introduce the forthcoming meeting of the Global Forum on Bioethics in Research

Calvin W. L. Ho

medhwlc@nus.edu.sg

1 Centre for Biomedical Ethics (CBmE), Yong Loo Lin School of Medicine, National University of Singapore, Singapore

2 Secretariat, Global Forum on Bioethics in Research (GFBR), London, UK 
(GFBR), which will take place in Singapore later in the year. The GFBR is the principal global platform for debate on ethical issues pertaining to international health research. Its core aims are to give voice to low- and middle- income country (LMIC) perspectives in debates about global health research ethics and to promote collaboration.

The GFBR meets annually to address a specific topic in research ethics and is case study based. This approach enables participants to understand the practical issues "on the ground", particularly in low resource settings. Up to 100 participants are selected for each meeting through a competitive process. Participants come from a diverse range of disciplines, countries and career stages and awards are available to LMIC colleagues to cover travel and accommodation. A key feature of GFBR is to bring together colleagues who are upcoming and established in their field so, as one participant put it, they can exchange ideas while slowly passing on the torch to the next generation.

GFBR aims to inspire participants to take the meeting discussion back to their regional contexts and effect change locally. A fellowship scheme ${ }^{1}$ is open to all LMIC participants, providing a unique opportunity to apply to work in partnership with other attendees to further explore and address the ethical challenges that are identified during the meeting. Through its meeting and fellowship scheme, GFBR aims to strengthen the capacity of those involved to recognise and negotiate ethical issues in research. In turn, the participants lead the way in building capacity in their local contexts-for example, by advocating for change in practice and policy at their institutions or by turning the GFBR case studies into training materials for local researchers and research ethics committees.

In 2017, GFBR held two meetings in Bangkok - the main GFBR meeting and a satellite meeting. The main meeting ${ }^{2}$ focused on the 'Ethics of alternative clinical trial designs and methods in LMIC research'. Colleagues from India, Thailand, Myanmar and the Philippines presented on a range of issues including the ethics of stepped wedge trial designs and on guidance and regulation in the region. The meeting was attended by 93 participants from 35 countries and involved a range of international speakers. After the meeting, four fellowships were awarded, of which two related to activities in Asia: one was concerned with developing ethical guidelines for Controlled Human Infection Model studies in India, and another was for hosting an Asian regional workshop on ethical issues in innovative trial designs.

The GFBR satellite meeting ${ }^{3}$ focused on the 'Ethics of research with refugee and migrant populations', a topic that was considered appropriate, given the high number of labour migrants and refugees in the region. The meeting was arranged in collaboration with the Mahidol Oxford Tropical Medicine Research Unit (MORU), Thailand, and the National University of Singapore and was attended by 41 participants from 24 countries. Presentations included an overview of the research landscape and reflections on ethical challenges by a colleague from the International Organization for Migration in the Philippines. Case studies were presented by colleagues from Malaysia and Thailand. The cases addressed the ethics of trafficking research in the Mekong region, the work of the Tak Province Community Advisory Board-a community engagement

\footnotetext{
${ }^{1}$ http://www.gfbr.global/fellowships/

${ }^{2} \mathrm{http} / / /$ www.gfbr.global/past-meetings/12th-forum-bangkok-thailand-28-29-november-2017/

${ }^{3} \mathrm{http}: / / w w w . g f b r . g l o b a l / p a s t-m e e t i n g s / 12$ th-forum-satellite-bangkok-thailand-30-november-1-december$2017 /$
} 
initiative on the Thai-Myanmar border and a proposed model for independent crossinstitutional ethics review of research with vulnerable populations in the Malaysian context. The meeting sparked a collaboration between colleagues based in Malaysia who have since established an informal process of independent, rapid ethics review of research involving refugees and migrants.

On 12 and 13 November 2019, GFBR returns to Asia for a meeting on the theme 'Genome editing for human benefit: ethics, engagement and governance' ${ }^{\text {. The meet- }}$ ing responds to the quickening pace of innovation in this field, which has brought a series of ethical, social and legal questions forward. In particular, CRISPR-Cas9 has made more precise, simple and cheap editing of a genome a realistic possibility.

The meeting will take place in Singapore and has a broad focus on emerging applications of genome editing that are designed to benefit human health. Somatic and germline human genome editing research are within scope, along with gene drive research that is intended to prevent the transmission of disease by vectors to humans (e.g. mosquito control to prevent malaria). Common challenges presented by these applications include the need to negotiate a high degree of uncertainty and demonstrate technical feasibility and safety through complex risk assessments, social acceptability and the need for appropriate governance systems. These issues were starkly highlighted in 2018 when Jiankui He, a Chinese scientist, claimed he created twin girls with a modification using CRISPR-Cas9 to reduce the risk of HIV infection. The claim was met with international condemnation (Cyranoski and Ledford 2018). Clearly, the time is right for GFBR to address the global issue of genome editing research, in what promises to be another stimulating meeting.

We take this opportunity to thank our section editor, Owen Schaefer, and all contributors to this journal issue, and we look forward to meeting some of our readers who are participating in the GFBR later in the year.

\section{References}

Cyranoski, David, and Heidi Ledford. 2018. International outcry over genome-edited baby claim. Nature 563: 607-608. https://doi.org/10.1038/d41586-018-07545-0.

Duffillot, Sébastien. 2019. Re: Asian elephant conservation - too elephantocentric? Towards a biocultural approach of conservation. Asian Bioethics Review 11 (2). https://doi.org/10.1007/s41649-019-00088-0.

Intergovernmental Science-Policy Platform on Biodiversity and Ecosystem Services. 2019. IPBES Global Assessment on Biodiversity and Ecosystem Services. Unedited draft report. Accessed 6 June 2019. https://www.ipbes.net/system/tdf/ipbes_global_assessment_chapter_1_unedited_31 may.pdf?file=1 \&type=node \&id=35277.

Lainé, Nicolas. 2018. Asian elephant conservation: too elephantocentric? Towards a biocultural approach of conservation. Asian Bioethics Review 10 (4): 279-293. https://doi.org/10.1007/s41649-018-0070-z.

Lainé, Nicolas, and Serge Morand. 2019. Re: Asian elephant conservation: too elephantocentric? Towards a biocultural approach of conservation - a response to Duffillot: a long road ahead. Asian Bioethics Review 11 (2). https://doi.org/10.1007/s41649-019-00089-z.

Lajaunie, Claire, and Serge Morand. 2018. Guest editorial: a pragmatic approach of ethics in interdisciplinary research on biodiversity conservation. Asian Bioethics Review 10 (4): 241-243. https://doi.org/10.1007 /s41649-018-0073-9.

\footnotetext{
${ }^{4}$ http://www.gfbr.global/?fbclid=IwAR3k5iu39BNgAoDgCZhhP_PF0w-FnBDYlE8zPJjiFetHl4dS7m2Y3 YZja5A
} 
Morand, Serge, and Claire Lajaunie. 2019. Linking biodiversity with health and well-being: consequences of scientific pluralism for ethics, value and responsibilities. Asian Bioethics Review 11 (2). https://doi. org/10.1007/s41649-019-00076-4.

Ooi, Kanny. 2019. Re: The need for healthcare reforms: is no-fault liability the solution to medical malpractice? Asian Bioethics Review 11 (2). https://doi.org/10.1007/s41649-019-00090-6.

Rai, Shivkrit, and Vishwas H. Deviah. 2019. The need for healthcare reforms: is no-fault liability the solution to medical malpractice? Asian Bioethics Review 11 (1): 81-93. https://doi.org/10.1007/s41649-01900081-7.

UNEP-WCMC. 2016. The state of biodiversity in Asia and the Pacific: a mid-term review of progress towards the Aichi Biodiversity Targets. Cambridge: United Nations Environment Programme. Accessed 6 June 2019. https://www.cbd.int/gbo/gbo4/outlook-asiapacific-en.pdf.

Publisher's Note Springer Nature remains neutral with regard to jurisdictional claims in published maps and institutional affiliations. 